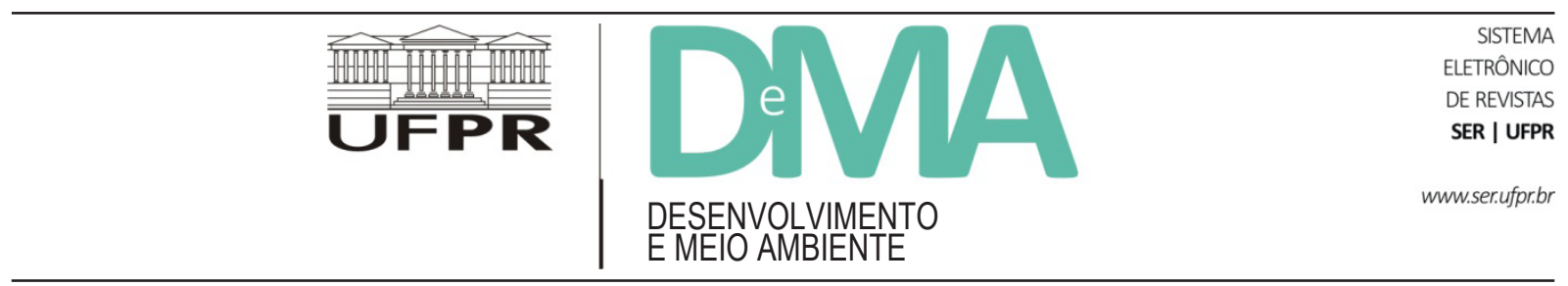

\title{
Análise de oportunidades e desafios para 0 Nexo Água-Energia
}

\section{Analysis of Opportunities and Challenges for the Water-Energy Nexus}

\author{
Leidiane MARIANI ${ }^{1,2 *}$, Marjorie Mendes GUARENGHI ${ }^{1}$, Jéssica Yuki Lima MITO², Carla Kazue Nakao \\ CAVALIERO $^{1,3}$, Rodrigo Régis de Almeida GALVÃO²
}

\footnotetext{
${ }^{1}$ Programa de Pós-Graduação Planejamento de Sistemas Energéticos (PSE), Universidade Estadual de Campinas (UNICAMP), Campinas, SP, Brasil.

${ }^{2}$ Centro Internacional de Energias Renováveis - Biogás, Parque Tecnológico Itaipu (PTI), Foz do Iguaçu, PR, Brasil.

${ }^{3}$ Faculdade de Engenharia Mecânica, Departamento de Energia, Universidade Estadual de Campinas (UNICAMP), Campinas, SP, Brasil.

*E-mail de contato: leidianemariani@yahoo.com.br
}

Artigo recebido em 2 de fevereiro de 2016, versão final aceita em 26 de abril de 2016.

RESUMO: O desenvolvimento econômico, o crescimento da população mundial e o aumento da urbanização, tendem a aumentar a demanda mundial por água e energia, intensificando os conflitos entre os setores hídrico e energético e gerando impactos sobre o meio ambiente. Além da interferência direta dos seres humanos sobre esses recursos, as mudanças climáticas e eventos climáticos extremos têm afetado a disponibilidade de água e, consequentemente, a geração de energia de forma significativa. Este trabalho tem como objetivos apresentar a dependência entre água e energia, ressaltando a importância de um planejamento integrado entre os setores hídrico e energético, e mostrar os principais desafios e oportunidades a serem enfrentados por pesquisadores, empresas e governos a fim de que o crescimento populacional e econômico seja pautado em decisões mais sustentáveis com relação ao nexo água-energia. Assim, é imprescindível que se considere o nexo água-energia no planejamento e na tomada de decisão dos governos em todos os níveis, desde o municipal até o nacional.

Palavras-chave: nexo água-energia; planejamento integrado de recursos; políticas públicas; meio ambiente.

ABSTRACT: The economic development, the population growth and the urbanization will increase water and energy world demand. As a consequence, the conflict between water resources and energy production will be intensified and the environment will be impacted by this competition. In addition to the direct influence of human activities, climate changes and extreme climate events have affected the water availability and, as consequence, the energy production. The aims of this article are to present the water-energy nexus and the importance of making an integrated planning between water and energy sectors. This article also presents the main challenges and opportunities that researchers, companies and governments will find in order to guide more sustainable 
decisions regarding the water-energy nexus. Thus, it is indispensable to consider the water-energy nexus in planning and government decision-making at all levels, from municipal to national.

Keywords: water-energy nexus; integrated resource planning; public policies; environment.

\section{Introdução}

A água, a energia e os alimentos são itens essenciais para a sobrevivência da humanidade, para a redução da pobreza e para o desenvolvimento sustentável, como afirma Hoff (2011) apud FAO (2014).

Apesar dessa importância, existe um risco de falta, pois vários estudos indicam que a demanda por esses itens irá crescer muito nas próximas décadas. Alguns dos motivos citados por Hoff (2011) apud FAO (2014) são o crescimento e a migração da população, o desenvolvimento econômico, o comércio internacional, a urbanização, a diversificação das dietas, as mudanças culturais e tecnológicas e as mudanças climáticas. Segundo OECD/FAO (2012) apud IRENA (2015), a demanda mundial por água, energia e alimentos irá crescer $50 \%, 80 \%$ e $60 \%$, respectivamente, entre 2000 e 2050 .

Segundo dados apresentados pela OECD (2012) e considerando apenas a demanda por recursos hídricos superficiais e subterrâneos (água azul), estima-se que a demanda de água no ano de 2050 seja de cerca de $5.500 \mathrm{~km}^{3}$ (crescimento de $55 \%$ com relação a 2000) devido principalmente aos aumentos na demanda para o setor industrial (400\%), para a geração de energia termelétrica (140\%) e para o uso doméstico (130\%). Neste cenário, os países do grupo BRIICS (Brasil, Rússia, Índia, Indonésia, China e África do Sul) seriam responsáveis por $60 \%$ da demanda hídrica global, pois se espera que terão destaque no crescimento econômico em relação aos outros países até 2050 .
Para esses países, a geração de eletricidade e o setor industrial provavelmente terão o maior aumento na demanda de água.

Em uma análise desses mesmos dados, a UNESCO (2003) também destaca que essas estimativas não levam em conta os fluxos ambientais necessários para o abastecimento futuro de água e para os serviços ecossistêmicos à base de água. Somando-se todos esses usos e fluxos e o crescimento previsto, o risco de pressão sobre os recursos hídricos se intensifica.

Especificamente sobre a água, sabe-se de suas restrições de disponibilidade e qualidade em lugares e momentos diferentes. Apenas 2,5\% da água do planeta é água doce. Desses $2,5 \%, 70 \%$ estão congelados em geleiras e não são disponíveis e apenas 30\% estão disponíveis em rios, aquíferos, lagos naturais e reservatórios (UNESCO, 2003). O Brasil tem uma posição privilegiada nesse sentido por possuir $12 \%$ da água doce superficial do planeta (ANA, 2009). Portanto, considerando que a água doce disponível e acessível é finita, conclui-se que poderá ocorrer uma pressão sobre esse recurso natural e uma concorrência entre seu uso para os diversos fins.

Da mesma forma que a água, a energia é um item essencial para os seres humanos e possui forte relação com as atividades econômicas e o desenvolvimento tecnológico. Em cenários apresentados pela OECD (2012) - 2010 e 2050 - estima-se que o PIB mundial deve ser quadruplicado até 2050, fazendo com que o uso de energia comercial total cresça cerca de $80 \%$, atingindo $900 \mathrm{EJ}^{1}$. Para o

\footnotetext{
Um exajoule (EJ) é igual a $1 \times 10^{18}$ joules.
} 
mesmo ano, espera-se uma redução de $40 \%$ na relação entre consumo de energia e PIB em virtude de melhorias contínuas de eficiência energética, com base nos níveis de 2010 .

Atualmente, os países considerados mais desenvolvidos consomem a maior parte da energia produzida mundialmente, porém os países emergentes e em desenvolvimento têm mostrado um papel importante na produção energética. No cenário projetado para 2050, assim como a água, os BRIICS apresentarão grande contribuição na produção de energia mundial (cerca de $45 \%$ ), enquanto os países da OECD e o resto do mundo contribuirão com cerca de $29 \%$ e $26 \%$, respectivamente. Dentre as fontes energéticas previstas, o carvão, o petróleo e o gás representarão maior participação na matriz energética global, mas energias não fósseis, como nuclear, biomassa e outras energias renováveis, também terão sua produção aumentada (OECD, 2012).

Historicamente, os temas energia e água ou energia, água e alimento são analisados e planejados separadamente, porém, com o aumento da interferência do ser humano no meio ambiente nas últimas décadas, e consequentes impactos, muitos estudos começaram a ser feitos para demonstrar a forte inter-relação entre esses temas e os riscos relacionados com a pressão de um sobre o outro.

Além disso, as mudanças climáticas previstas e os eventos climáticos extremos ocorridos também motivaram essa nova visão da interface entre água e energia. Isso se deve ao fato de que esses eventos geram secas ou inundações, afetando diretamente a disponibilidade de água e a produção de energia e de grãos para combustíveis e alimento.

Adicionalmente, os setores de água e energia não têm a mesma importância econômica e estratégica em um primeiro momento. Os impactos da falta de energia são sentidos muito rapidamente pelas indústrias e por todo o mercado, porém, os efeitos da falta de água são mais intensos sobre a população em geral e normalmente mais acentuados sobre as classes mais pobres. Ao mesmo tempo, os lucros com a produção e a venda de energia são muito mais impactantes para os países, sendo um exemplo o petróleo e seus derivados. Já a água, por ser um bem público e nem sempre ser tratado nas leis de mercado, passa a não ser um negócio tão atrativo (UNESCO, 2014).

Tendo em vista o crescimento populacional e econômico, as mudanças climáticas e os conflitos relacionados ao uso da água, este trabalho apresenta um panorama geral sobre a inter-relação entre água e energia e a importância da abordagem integrada desse nexo a fim de atingir um desenvolvimento mais sustentável. Também são apresentados riscos envolvidos no uso desequilibrado de um recurso sobre o outro, além de mostrar ferramentas que auxiliem no planejamento integrado dos setores hídricos e energéticos, assim como os desafios e oportunidades que governos, empresas, pesquisadores e a comunidade têm pela frente com relação ao nexo água-energia.

\section{O nexo entre água e energia}

Segundo a UNESCO (2014), aproximadamente $90 \%$ da produção global de energia elétrica é intensiva no uso de água. A água é usada diretamente para a produção de energia hidrelétrica tanto quanto para a produção de energia térmica. Essas duas fontes de energia ainda são essenciais para os sistemas energéticos da maioria dos países, por proporcionarem energia estável ao longo do dia e permitirem armazenamento de sua fonte - água ou combustível. Fontes menos dependentes de água, como a eólica e a solar, apesar do aumento da 
participação na matriz energética mundial, geram energia elétrica de forma intermitente, não garantindo o abastecimento base do sistema elétrico.

De acordo com o gráfico da Figura 1 de Metzger et al. (2016), com dados da intensidade de consumo de água $\left(\mathrm{m}^{3} /\right.$ milhões de US\$) e de consumo de energia (MWh/milhões de US\$) das principais indústrias mundiais, o setor de óleo, gás e carvão, juntamente com o setor de concessionárias de energia, estão entre os três setores mais intensivos. Esses dados reiteram a dependência que o setor energético tem dos recursos hídricos para sua manutenção e crescimento.

\section{1. Água no setor energético}

A Agência Internacional de Energia (IEA, 2012) apresenta um quadro com os principais usos de água para a geração de energia e os potenciais impactos na qualidade da água relacionados, conforme a Tabela 1.

Em alguns casos, fica clara a relação entre a água e a energia, como é o da geração hidrelétrica, pois a quantidade de água disponível interfere diretamente na quantidade de energia elétrica gerada. Porém, como a qualidade da água utilizada não interfere diretamente na produção de energia, fica, muitas vezes, relegada
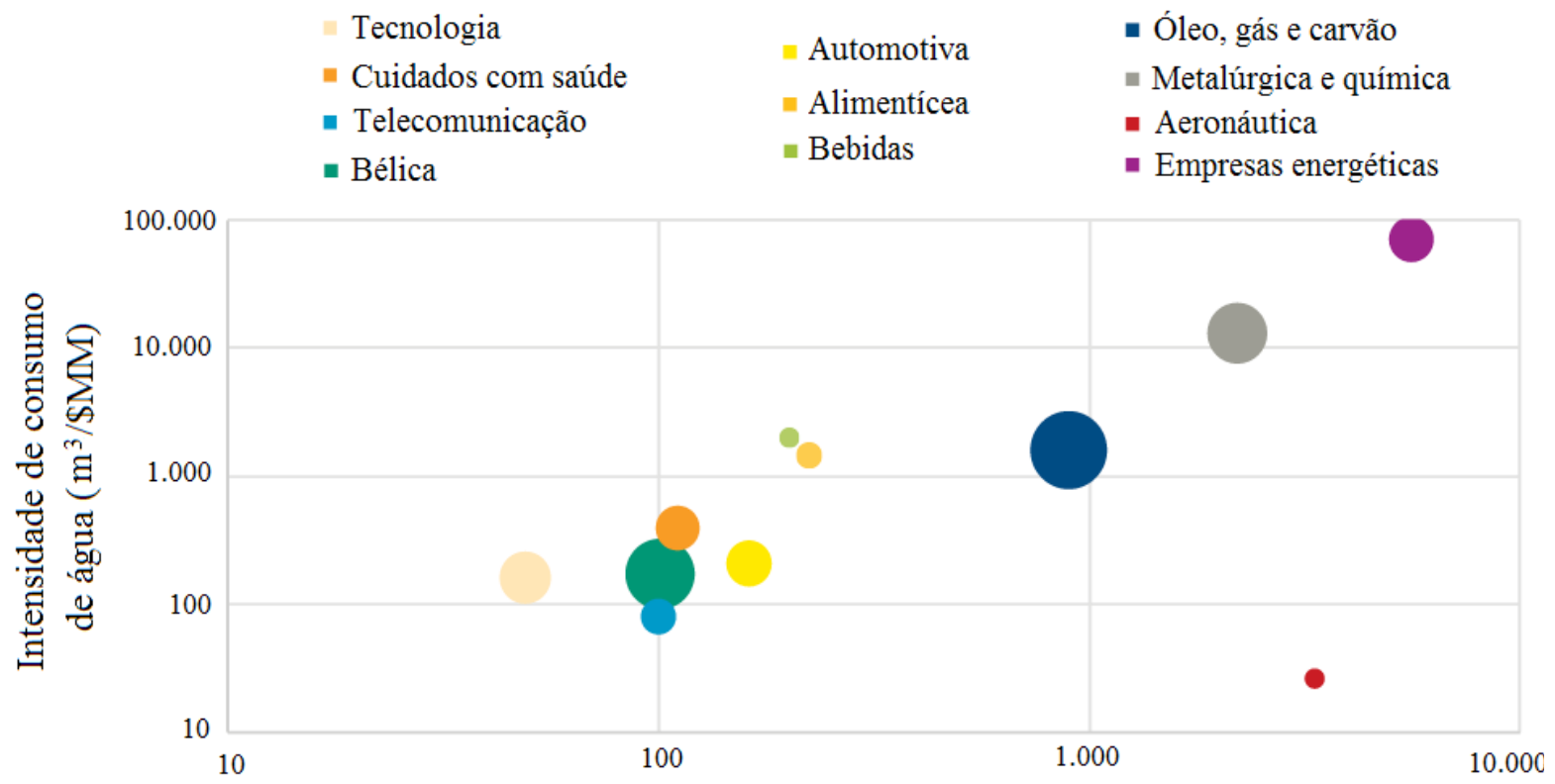

Intensidade energética $(\mathrm{MWh} / \mathrm{SMM})$

FIGURA 1 - Intensidade do consumo de energia e água das principais indústrias.

FONTE: Metzger et al. (2016). 
TABELA 1 - Principais usos de água para a geração de energia e os potenciais impactos na qualidade da água.

\begin{tabular}{|c|c|c|}
\hline & Usos & Potenciais impactos na qualidade da água \\
\hline \multicolumn{3}{|c|}{ PRODUÇÃO DE ENERGIA PRIMÁRIA } \\
\hline Óleo e gás & $\begin{array}{l}\text { Perfuração, acabamento de poços e da } \\
\text { fraturação hidráulica. } \\
\text { Injeção para o reservatório secundário e } \\
\text { recuperação de óleo aprimorada. } \\
\text { Mineração de areias petrolíferas e recuperação } \\
\text { in situ. } \\
\text { Upgrading e refino para produtos. }\end{array}$ & $\begin{array}{l}\text { Contaminação por rejeitos infiltrados, fluidos } \\
\text { de fraturamento, fluxo de retorno ou água } \\
\text { produzida (superficial e subterrânea). }\end{array}$ \\
\hline Carvão & $\begin{array}{l}\text { Corte e supressão de poeira em mineração e } \\
\text { transporte. } \\
\text { Lavagem para melhorar a qualidade do carvão. } \\
\text { Reflorestamento da superficie de áreas de } \\
\text { mineração. } \\
\text { Transporte de longa distância via lama de } \\
\text { carvão. }\end{array}$ & $\begin{array}{l}\text { Contaminação por rejeitos infiltrados, drenagem } \\
\text { da mina ou da água produzida (superficial e } \\
\text { subterrânea). }\end{array}$ \\
\hline Biocombustíveis & $\begin{array}{l}\text { Irrigação para o crescimento dos cultivos } \\
\text { agrícolas. } \\
\text { Moagem úmida, lavagem e arrefecimento no } \\
\text { processo de conversão de combustível. }\end{array}$ & $\begin{array}{l}\text { Contaminação por escoamento superficial } \\
\text { contendo fertilizantes, pesticidas e sedimentos } \\
\text { (superficiais e subterrâneos). } \\
\text { Efluentes produzidos no refino. }\end{array}$ \\
\hline \multicolumn{3}{|c|}{ GERAÇÃO DE ENERGIA } \\
\hline $\begin{array}{l}\text { Térmica } \\
\text { (combustível } \\
\text { fóssil, nuclear e } \\
\text { bioenergia) }\end{array}$ & $\begin{array}{l}\text { Alimentação de caldeiras, ou seja, a água } \\
\text { utilizada para gerar vapor ou água quente. } \\
\text { Arrefecimento por vapor condensado. } \\
\text { Purificação de poluentes utilizando } \\
\text { equipamentos de controle de emissões. }\end{array}$ & $\begin{array}{l}\text { Poluição térmica pela água de descarga do } \\
\text { arrefecimento (água de superfície). } \\
\text { Impactos nos ecossistemas aquáticos. } \\
\text { Emissões atmosféricas que poluem a água na } \\
\text { direção do vento (água de superfície). } \\
\text { Descarga de purga de caldeiras, ou seja, da } \\
\text { alimentação da caldeira que contém sólidos em } \\
\text { suspensão. }\end{array}$ \\
\hline $\begin{array}{l}\text { Concentração de } \\
\text { energia solar e } \\
\text { geotérmica }\end{array}$ & $\begin{array}{l}\text { Fluidos dos sistemas ou de alimentação da } \\
\text { caldeira, ou seja, a água utilizada para gerar } \\
\text { vapor ou água quente. } \\
\text { Arrefecimento por vapor condensado. }\end{array}$ & $\begin{array}{l}\text { Poluição térmica por descarga de água do } \\
\text { arrefecimento (água de superfície). } \\
\text { Impacto nos ecossistemas aquáticos. }\end{array}$ \\
\hline Energia hídrica & $\begin{array}{l}\text { Geração da eletricidade. } \\
\text { Armazenamento em um reservatório } \\
\text { (para operar usinas hidrelétricas ou para } \\
\text { armazenamento de energia). }\end{array}$ & $\begin{array}{l}\text { Alteração de temperatura da água, fluxo de } \\
\text { volume/tempo e dos ecossistemas aquáticos. } \\
\text { Perdas por evaporação do reservatório. }\end{array}$ \\
\hline
\end{tabular}

FONTE: IEA (2012). 
a um patamar inferior na escala de prioridades da usina, tendo menos foco e investimentos.

Apesar de tradicionalmente a energia hidrelétrica ser conhecida pela total dependência de água na sua produção, outras fontes de energia também se destacam na demanda por água. Segundo dados da IEA (2012) apresentados na Figura 2, os biocombustíveis produzidos a partir de grãos são as fontes de energia que mais consomem água, destacando-se o etanol de milho e de cana-de-açúcar e o biodiesel de soja. A variação da necessidade de água para esses biocombustíveis depende da região e do sistema de produção dos grãos, sendo influenciada principalmente pelo uso da irrigação; os menores valores correspondem às culturas não irrigadas, nas quais apenas é apresentada a água necessária para a etapa industrial de fabricação do biocombustível. Quando utilizada a irrigação, esses combustíveis podem demandar a captação de até $1.000 \mathrm{~m}^{3}$ de água por tonelada equivalente de petróleo, representando valores consideráveis.

Em um patamar inferior, mas ainda importante de consumo, estão alguns combustíveis fósseis, como o carvão, os óleos refinados e o gás de xisto, com captação de até $1 \mathrm{~m}^{3}$ de água por tonelada equivalente de petróleo. Apesar de terem uma demanda menor por água, essas fontes de energia causam outros impactos ao meio ambiente ao serem consumidas, como o aumento de emissões causadoras do efeito estufa e poluição do ar das cidades.

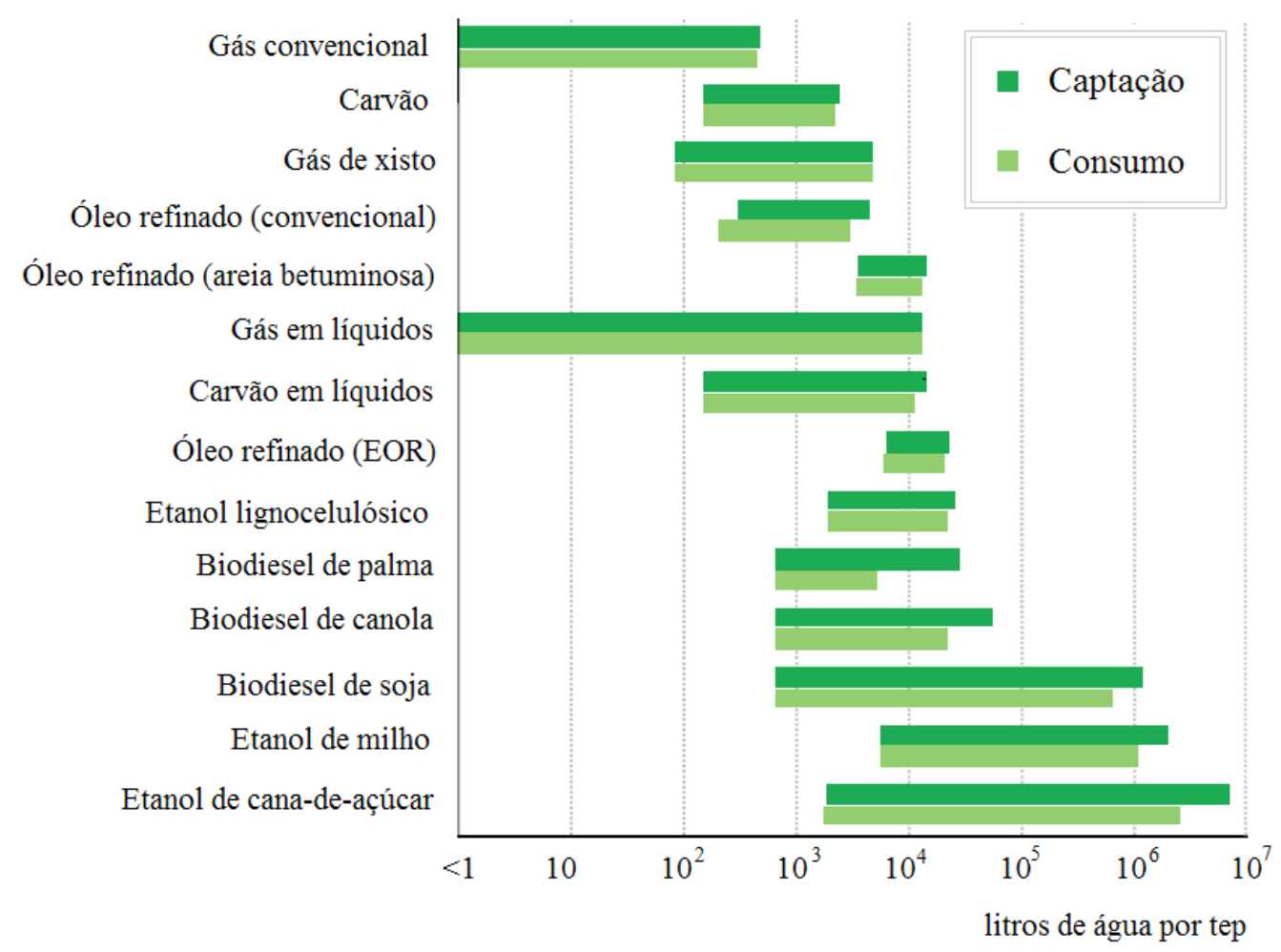

FIGURA 2 - Captação e consumo de água por fonte de energia primária. FONTE: IEA (2012). 
Para se ter uma noção da ordem de grandeza do uso de água pelo setor energético mundial, pode-se analisar os dados da IEA (2012), onde se estimou que a captação global de água doce para a produção de energia em 2010 foi de 583 bilhões de metros cúbicos, cerca de $15 \%$ da captação total de água do mundo (Figura 3). Já a água efetivamente consumida para a produção de energia foi de 66 bilhões de metros cúbicos no mesmo ano, ou cerca de $11 \%$ da captação de água relacionada com a obtenção de energia.

Nesse mesmo estudo da IEA, estimou-se a quantidade de água a ser captada em 2020 e 2035 para diferentes cenários de políticas públicas (Figura 3). No cenário que reflete a continuidade das políticas atuais, a quantidade de água captada pelo setor energético mundialmente aumentaria para quase 800 bilhões de metros cúbicos em 2035, um aumento de cerca de $37 \%$ com relação a 2010 . Em um cenário de novas políticas, o aumento seria metade desse valor, cerca de $20 \%$.

O detalhamento dos dados de captação e consumo de água para o setor energético, considerando um cenário de novas políticas e dividindo-se por tipo de energia e combustível é apresentado na Figura 4. Observa-se que em 2010 o setor de carvão foi o que mais captou e consumiu água em relação às outras fontes, mas que a tendência é que o uso de água para produção de biocombustíveis aumente bastante, em valores totais, devido ao crescimento de sua produção.

Ou seja, o aumento da demanda de água ocorrerá mesmo em cenários que prevejam a mudança das políticas de incentivo à redução de consumo de água no setor energético. Isso pressionará o uso desse recurso e poderá causar conflitos entre países ou entre setores.

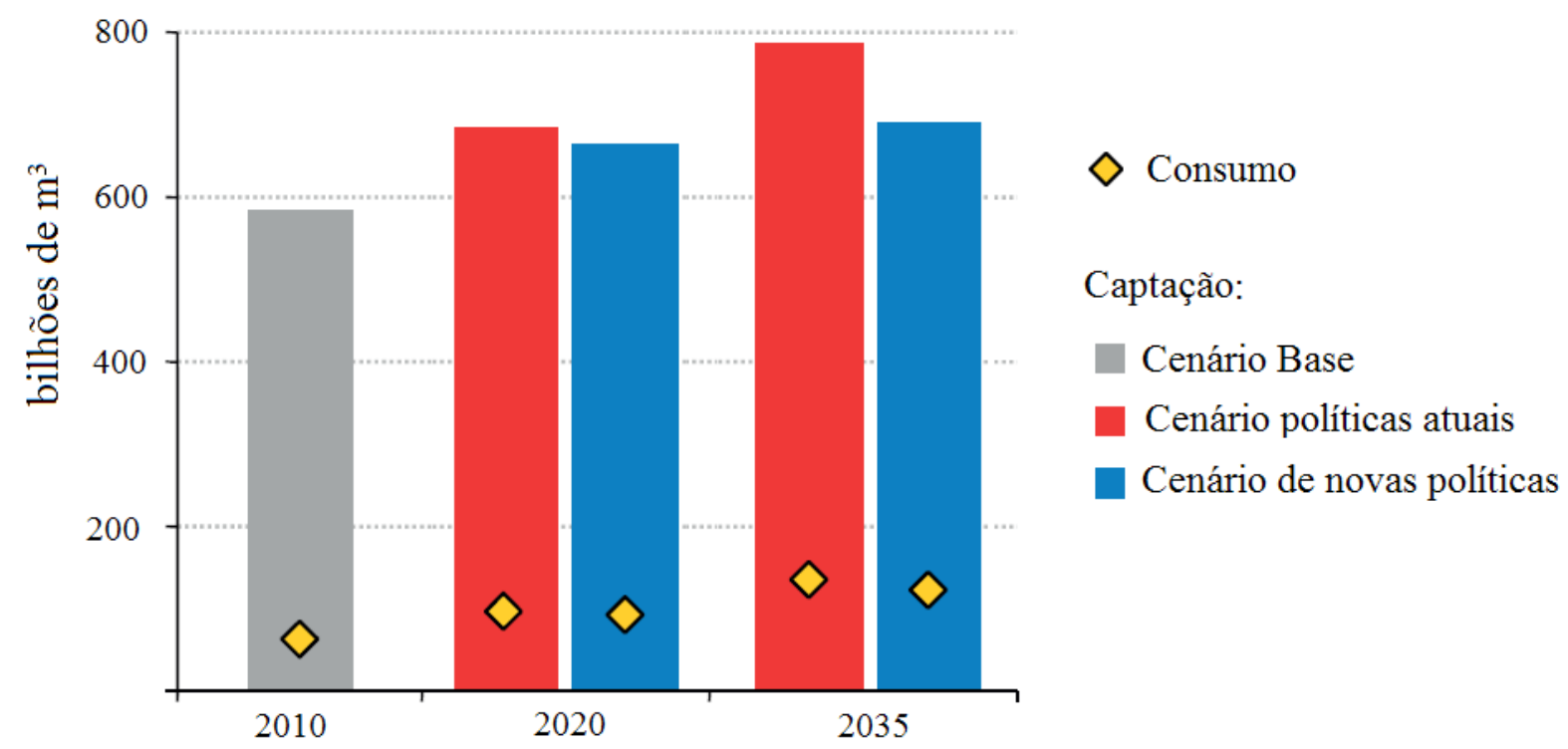

FIGURA 3 - Captação e consumo de água no setor energético mundial. FONTE: IEA (2012). 

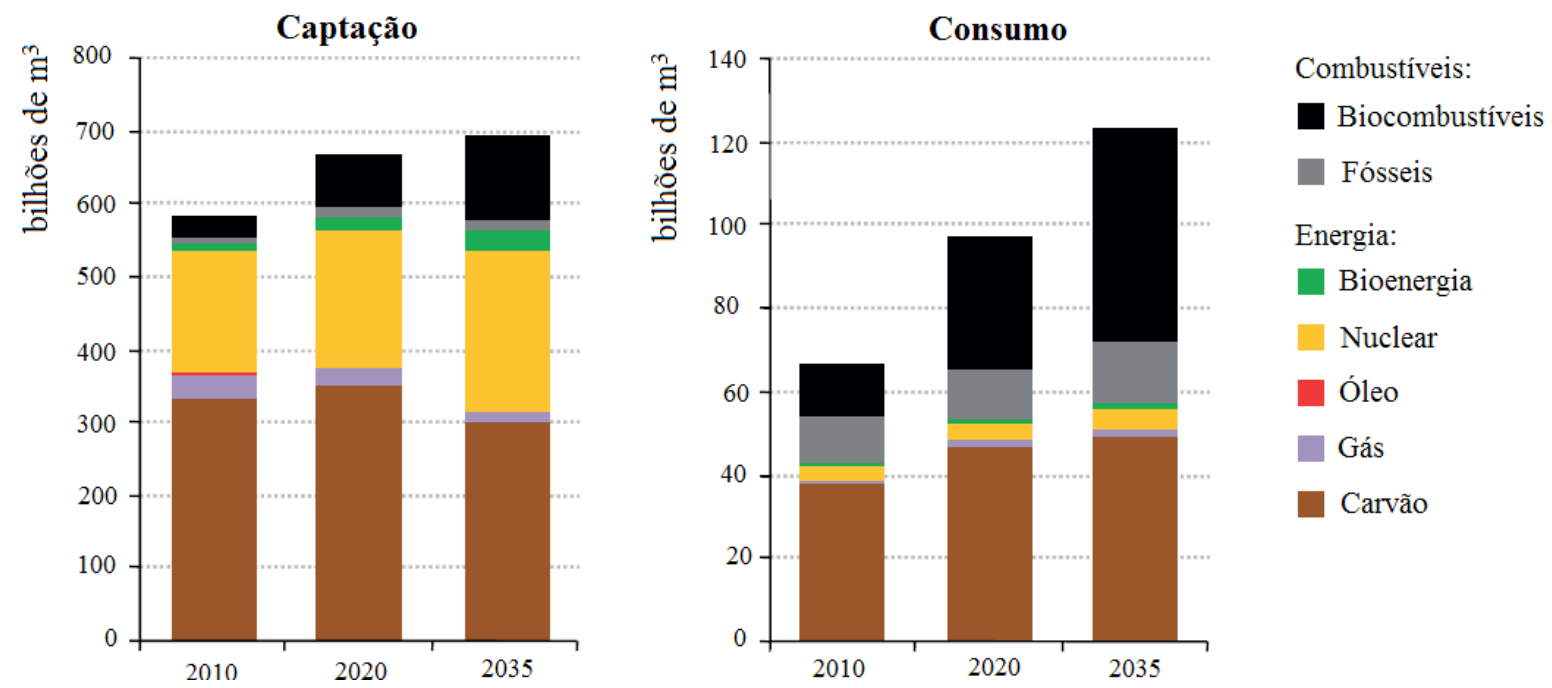

FIGURA 4 - Captação e consumo de água no setor energético mundial por tipo de geração de energia e combustível para o cenário de novas políticas.

FONTE: IEA (2012).

\subsection{Energia no setor hídrico}

A outra metade do nexo água-energia refere-se ao consumo de energia para o abastecimento e tratamento de água. O processo demanda energia elétrica para bombear água dos rios e poços para a superfície, transportar até uma estação de tratamento, tratar e distribuir para a população.

No caso da captação de água, a demanda energética varia com a distância e com a profundidade das fontes hídricas utilizadas. Grandes centros urbanos normalmente precisam trazer água de longas distâncias para suprir a demanda da população, aumentando a demanda energética para a captação.

Para converter a água bruta (fresca, salobra, salgada ou esgoto) em água potável passível de consumo, os processos de tratamento requerem energia para a agitação e a mistura das substâncias com a água e, algumas vezes, até calor. Segundo a IEA (2012), o processo de dessalinização, por exemplo, é a alternativa de tratamento de água mais energeticamente intensiva e cara e por isso acaba sendo utilizada apenas quando as opções são muito restritas, como em regiões desérticas.

Também se consome energia elétrica no bombeamento da água tratada para os sistemas de armazenamento e distribuição para a população. Em geral, quanto mais próximas as fontes de água estão localizadas dos locais de consumo, menor a energia necessária para sua distribuição. Como pode ser observado na Figura 5, a menor intensidade energética é dada pela captação a partir de rios e lagos. O abastecimento a partir de mananciais subterrâneos passa a ter uma maior energia devido ao bombeamento da água para a superfície. Dentre as fontes de água, o uso da água do mar apresenta uma intensa demanda energética, que ocorre em função da temperatura da água e de sua salinidade. Após o consumo, os efluentes industriais e esgotos domésticos também precisam ser bombeados para as estações de tratamento, demandando mais energia para esses processos. 


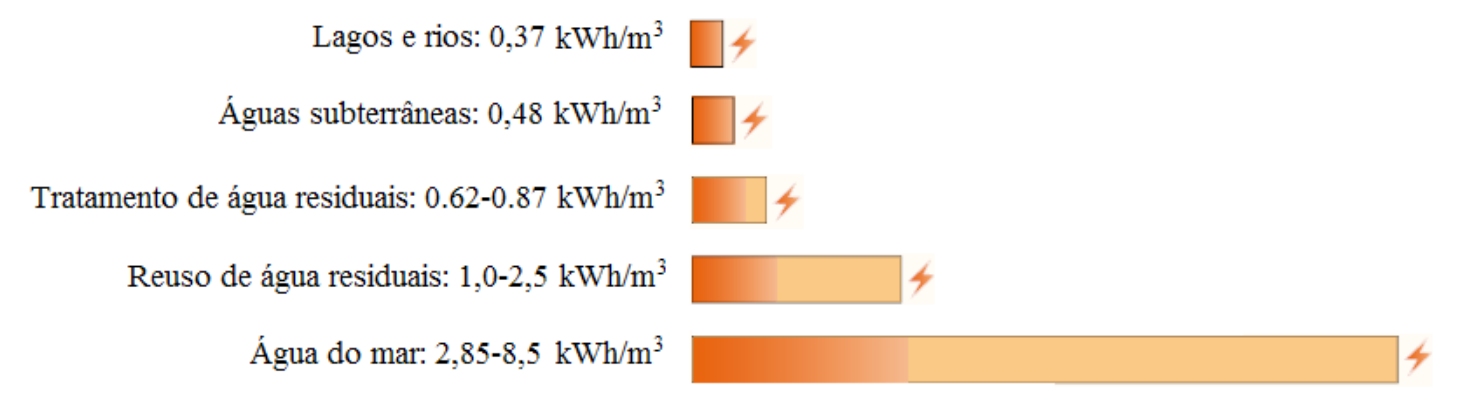

FIGURA 5 - Quantidade de energia necessária para prover $1 \mathrm{~m}^{3}$ de água potável para o ser humano, de acordo com a fonte de água. FONTE: UNESCO (2014).

Olhando para o futuro, várias tendências apontam para aumento da demanda em energia no setor da água, segundo a IEA (2012):

- Aumento da demanda de água, como resultado do crescimento da população e melhores padrões de vida;

- Fontes de água doce escassas na proximidade dos centros populacionais, devido às mudanças climáticas. Isto significa que a água terá de ser transportada por distâncias mais longas, bombeada de grandes profundidades ou submetida a um tratamento adicional;

- Normas mais rigorosas para tratamento de água;

- A mudança geral nas práticas de irrigação de superfície ou inundação (contando com gravidade) para os métodos de bombeamento, que são mais eficientes em termos de água, mas necessitam de energia para a operação.

Nesse sentido, a UNESCO (2014) cita um lado notável e interessante do nexo água-energia que é o de o esgoto e os efluentes serem encarados como fontes de energia, ao invés de apenas resíduos. $\mathrm{Na}$ maioria dos projetos em desenvolvimento no mundo, o biogás produzido no processo anaeróbio de tratamento dos efluentes é aproveitado para gerar energia elétrica ou para secagem do lodo resultante.

\section{Conceituação dos nexos água-energia e água-energia-alimento}

O tema nexo água e energia vem sendo estudado nos últimos anos no sentido de que programas de governo, leis e regulamentações considerem essa relação. Vale ressaltar que tradicionalmente se discute o nexo água-energia-alimento, ao invés de apenas água-energia, devido à forte relação entre eles e ao impacto na sobrevivência dos humanos. Algumas definições também incluem o clima ou a biodiversidade no nexo, conforme o âmbito e o foco da análise.

No âmbito global, o tema foi discutido em alguns eventos ou publicações listados a seguir:

- Publicação Segurança Hídrica: o nexo água-alimento-energia-clima ou Water Security: The Water-Food-Energy-Climate Nexus, do Fórum Econômico Mundial em 2011 (WEF, 2011a);

- Conferência de Bonn em 2011, sobre a interdependência entre água, energia e segurança alimentar (Hoff, 2011); 
- A Conferência Rio+20 em 2012, destacando as relações entre água, energia e alimento, nutrição e sustentabilidade, cidades sustentáveis, saúde, biodiversidade e desertificação (ONU, 2012);

- A Conferência Climática da Organização das Nações Unidas - COP18 - realizada em Doha no Qatar, em 2012, descrevendo o nexo água, energia e alimento como a face humana e a solução para as mudanças climáticas (WMO, 2012);

- As publicações do Fórum Econômico Mundial denominadas Riscos Globais de 2011 e Riscos Globais de 2015, citando o nexo água, energia e alimento como uma questão para a segurança global (WEF, 2011b; WEF, 2015).
Como forma de facilitar a compreensão do conceito proposto para o nexo água-energia-alimento e os fatores que interferem nessa relação, vários desenhos esquemáticos foram criados.

Um deles é o de Hoff (2011), que pode ser visualizado na Figura 6. O esquema é centrado no abastecimento de água, energia e segurança alimentar, todos ligados aos recursos hídricos disponíveis e sofrendo a interferência das tendências globais, incluindo a urbanização, o crescimento populacional e a mudança climática. Por meio de recursos financeiros, governança e inovações, o objetivo é promover a água, energia e segurança alimentar para todos; crescimento equitativo e sustentável; e um ambiente flexível e produtivo. Este objetivo pode ser atingido por meio de campos de ação e medidas específicas ao acelerar o acesso e a inte-

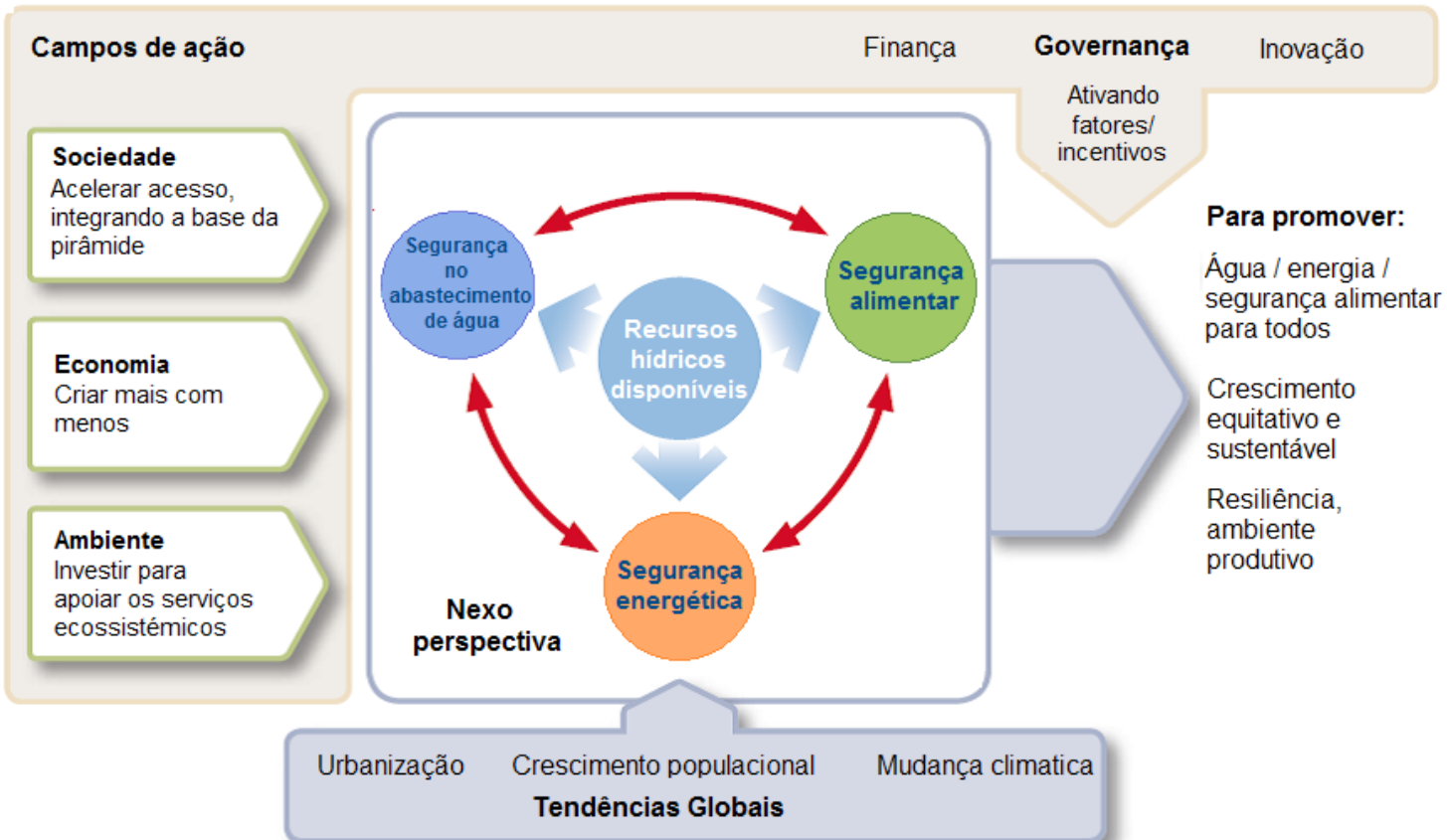

FIGURA 6 - O nexo água-energia-alimento segundo a Conferência de Bonn, 2011.

FONTE: Hoff (2011). 
gração da base da pirâmide (sociedade), a criação de mais com menos (economia) e o investimento para apoiar os serviços ecossistêmicos (ambiente).

Para a United Nations Economic Commission for Europe - UNECE (2015), a Conferência Internacional sobre o nexo água, energia e segurança alimentar - Soluções para uma Economia Verde, que ocorreu em Bonn em 2011, trouxe mais atenção sobre essas interligações e apresentou evidências iniciais sobre como uma abordagem sobre o nexo pode melhorar a segurança hídrica, energética e alimentar por meio do aumento da eficiência, da redução de perdas, da construção de sinergias e da melhoria da governança em todos os setores.

O WEF (2011b) destaca que a segurança hídrica, a segurança alimentar e a segurança energética são impedimentos crônicos para o crescimento econômico e a estabilidade social e os analisa com um enfoque de riscos. Essa relação é representada no esquema da Figura 7, em que fica clara a interdependência entre os três elementos, além das interferências do crescimento econômico e populacional e das pressões ambientais. Ademais, falhas de governança em termos de gestão de recursos partilhados, como fontes de água e energia transfronteiriças e acordos comerciais de alimentos, criam tensões que podem levar a conflitos. As desigualdades econômicas também exacerbam esse nexo de riscos, já que os governos e os consumidores procuram soluções de curto prazo e insustentáveis para as dificuldades econômicas (WEF, 2011a).

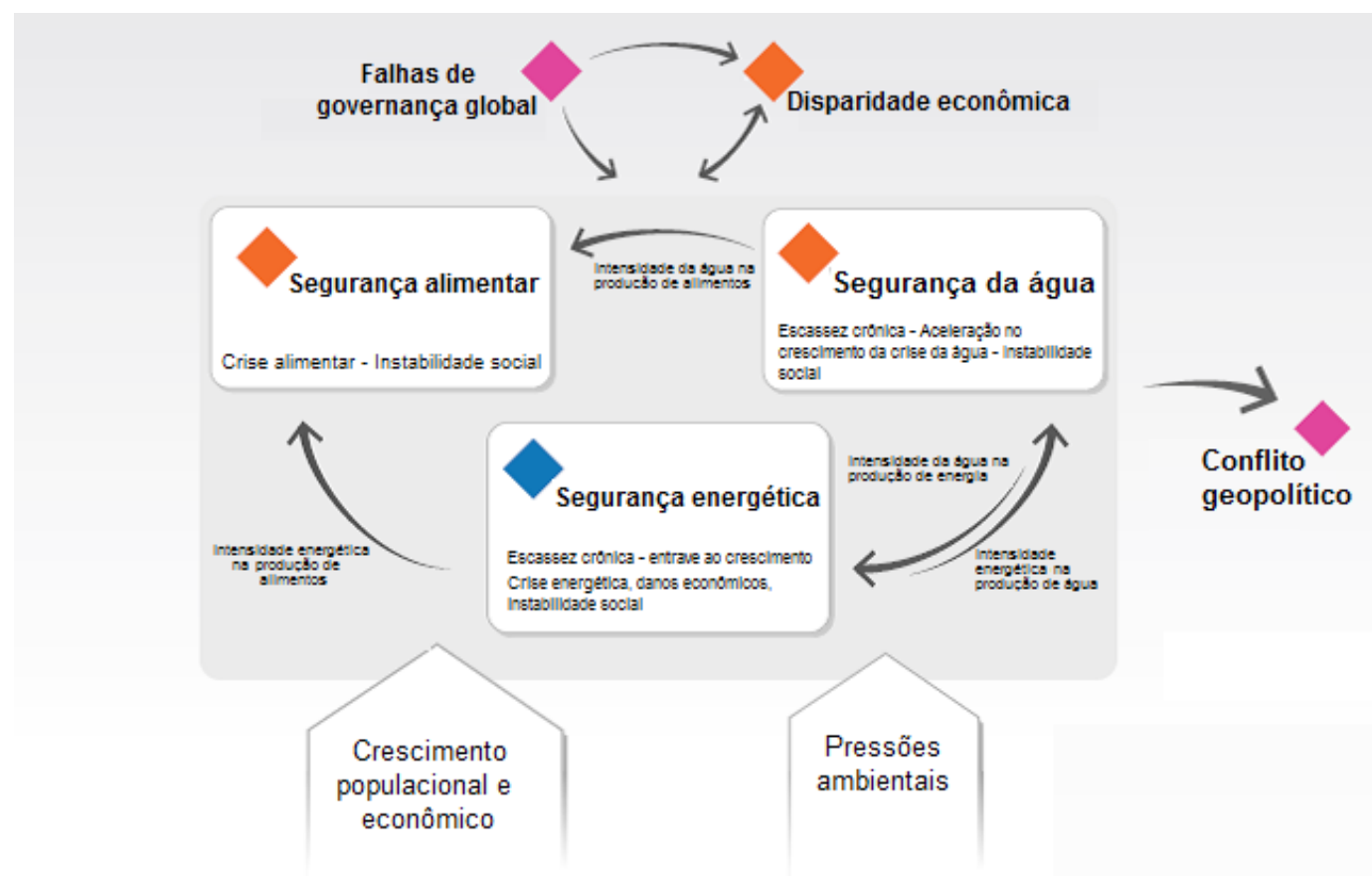

FIGURA 7 - Riscos associados com o nexo água-energia-alimento. FONTE: WEF (2011a). 
Um terceiro esquema baseia-se nos serviços ecossistêmicos, como exemplificado pela Figura 8. O esquema foi desenvolvido pelo International Centre for Integrated Mountain Development ICIMOD - para abordar estudos de caso no Himalaia e sul da Ásia. Segundo ICIMOD (2012) apud Bizikova et al. (2013), com esse enfoque o nexo é visto como um sistema global, mais que setorial, o que pode reduzir perdas e aumentar os benefícios. No sul da Ásia, por exemplo, essa abordagem precisa necessariamente levar em conta o ecossistema do Himalaia.

Esses três esquemas foram analisados mais detalhadamente por Bizikova et al. (2013) e sua conclusão foi:

Em termos de elementos-chave dos três esquemas apresentados, todos se concentram em promover a segurança e considerar o envolvimento de diferentes domínios: a sociedade, mudando comportamentos humanos; a economia, usando diferentes abordagens para o crescimento econômico; e o meio ambiente, através da promoção de serviços ecossistêmicos (Bizikova et al., 2013).

Da mesma forma, a IRENA (2015) propõe um esquema adaptado de Mohtar \& Daher em 2012, apresentado na Figura 9. Segundo a agência, as conexões entre água, energia e alimento se intensificam com o aumento da demanda por recursos causada pelo crescimento populacional e pelas mudanças dos padrões de consumo. Ao mesmo tempo, tendências mundiais, como as mudanças climáticas e a competição pelo uso do solo, restringem a habilidade dos sistemas existentes de atender à crescente demanda de maneira confiável

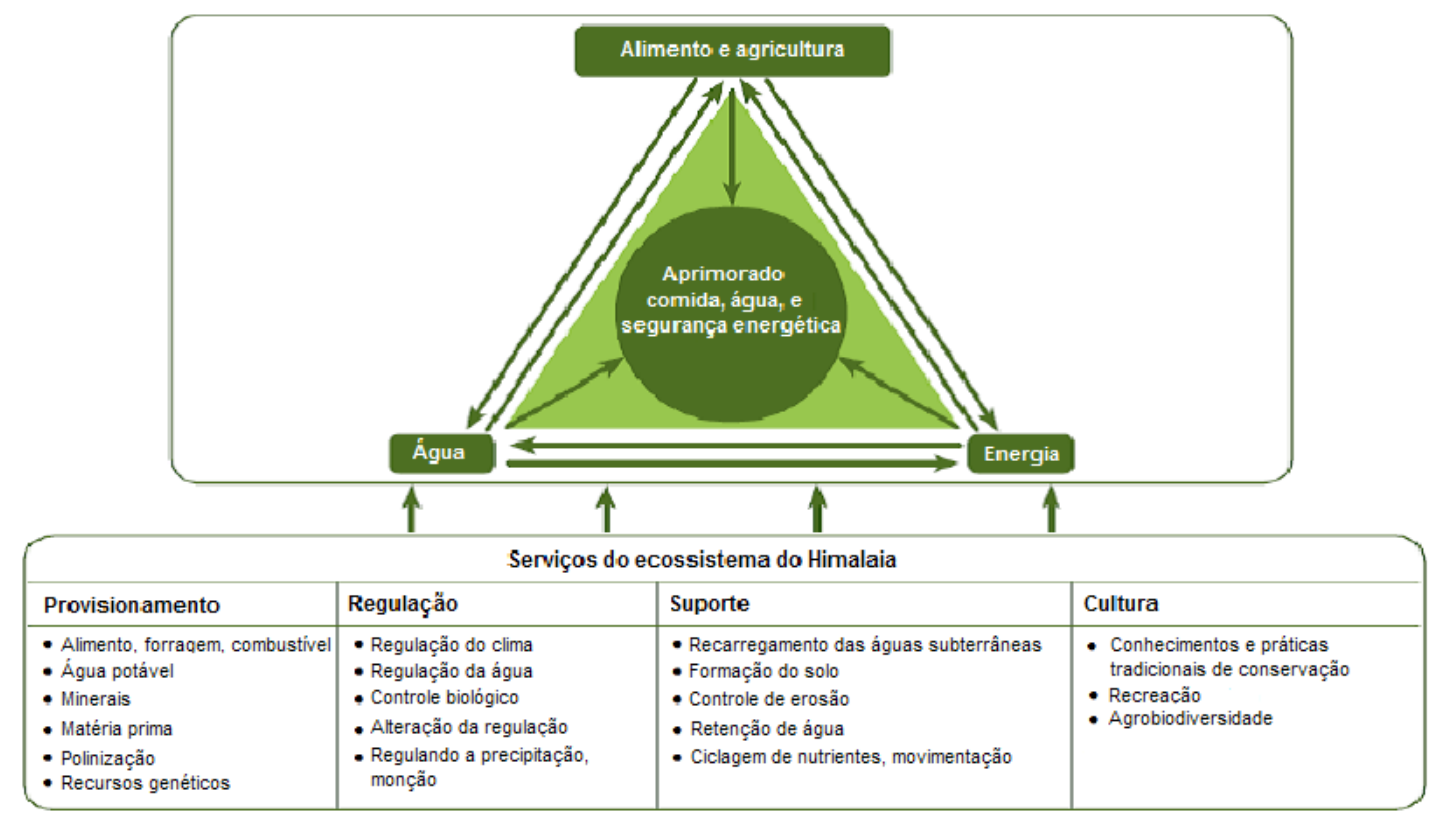

FIGURA 8 - Enfoque do nexo água-energia-alimento desenvolvido pelo ICIMOD.

FONTE: ICIMOD (2012) apud Bizikova et al. (2013). 


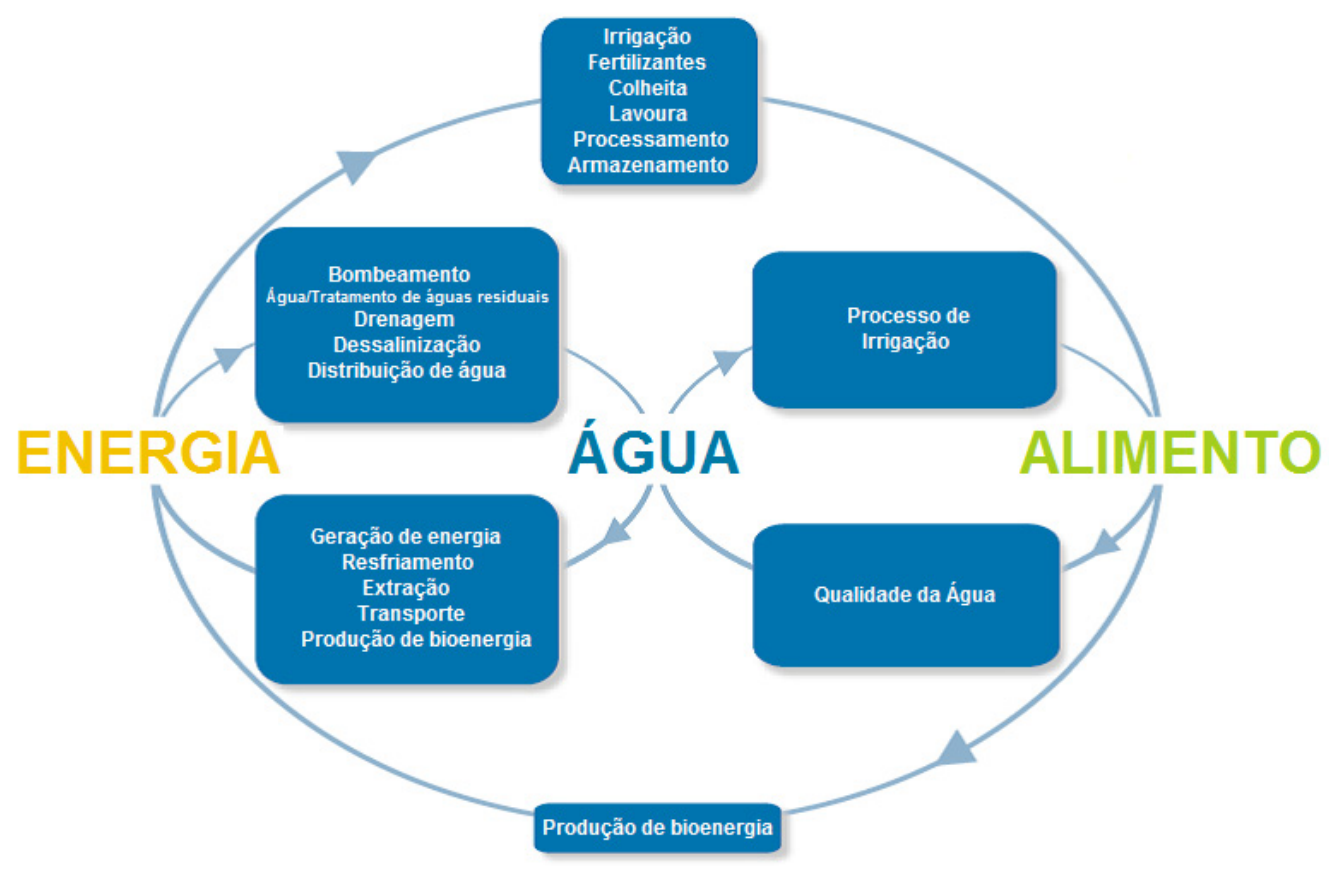

FIGURA 9 - Desenho esquemático do nexo água-energia-alimento, segundo a IRENA.

FONTE: IRENA (2015).

e acessível. Essa dinâmica gera riscos substanciais para o desenvolvimento sustentável e para a segurança dos recursos de muitos governos, negócios e comunidades.

A relação água-energia-alimento, portanto, representa uma abordagem conceitual que possibilita a observação e a análise das interações entre as atividades humanas e o meio ambiente, a fim de fornecer subsídios para uma gestão mais coordenada e sustentável entre a utilização dos recursos naturais e o desenvolvimento humano (FAO, 2014). Em virtude da forte relação e interdependência entre esses elementos, as escolhas feitas em um domínio têm consequências diretas e indiretas, positivas e negativas um sobre o outro (IEA, 2012; UNESCO, 2014).

\section{Impactos e riscos relacionados ao nexo água-energia}

Considerando a importância isolada e inter-relacionada dos elementos água e energia, e também água, energia e alimento, os impactos que podem ser causados pelo desequilíbrio na disponibilidade de um ou outro podem ser catastróficos. Como citado pelo WEF (2011b), a escassez poderia causar instabilidade social e política, conflitos geopolíticos e danos ambientais irreparáveis.

Com o crescimento da demanda por água, energia e alimento no mundo, detalhado na Figura 10 , espera-se, consequentemente, que a inter-relação entre esses elementos também se intensi- 
fique. Caso ocorra um crescimento desequilibrado entre esses componentes, riscos podem surgir. Por exemplo, considerando o cenário estimado para 2050 , se a demanda energética for superior a $80 \%$ e a demanda de água se mantiver em $55 \%$, o setor energético aumentaria sua pressão sobre o setor hídrico mais do que o oposto, provavelmente gerando concorrência pelos recursos, que são finitos.
Portanto, a produção energética pode ser limitada ou restringida de acordo com os potenciais riscos que podem acarretar ao meio ambiente. Dependendo da fonte energética, tanto a disponibilidade da água pode ser comprometida como também a qualidade com a contaminação de cursos d'água superficiais e lençóis subterrâneos. Alguns exemplos podem ser citados, como: um projeto de carvão

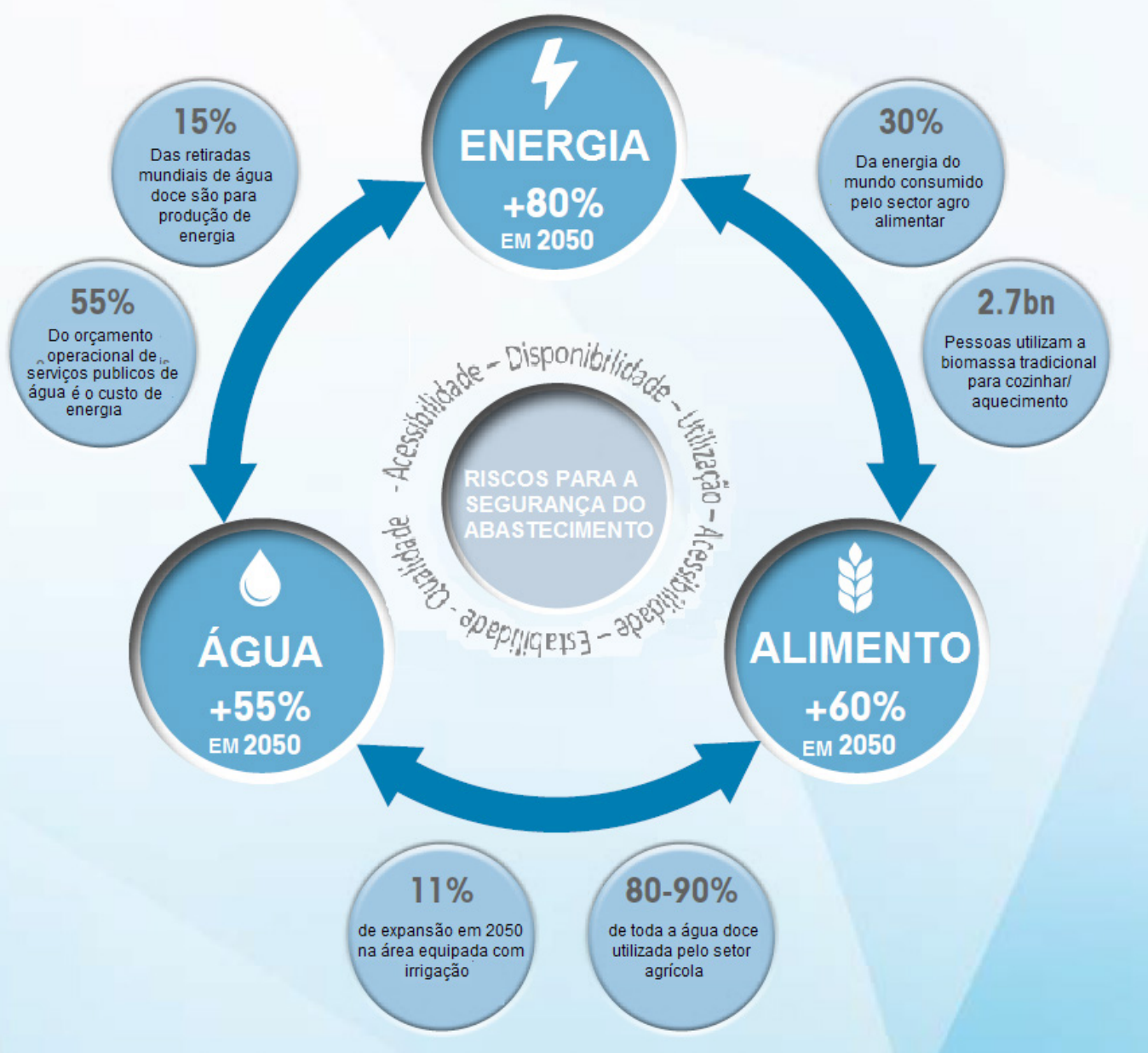

FIGURA 10 - Estimativa do crescimento das demandas em 2050 e detalhes do nexo água-energia-alimento. FONTE: IRENA (2015). 
químico na região da Mongólia Interior, China, cuja exploração hídrica foi tão intensa durante oito anos que acarretou uma redução de até $100 \mathrm{~m}$ no nível de água no lençol freático, diminuindo um lago na região em $62 \%$, forçando moradores a mudarem de local; também na China, diversos projetos de carvão para líquidos (CLT) planejados foram abandonados, em parte devido às preocupações com a grande pressão sobre os recursos hídricos escassos; na África do Sul, uma central elétrica a carvão, atualmente em construção, tem uma demanda estimada em 2,9 milhões de litros de água por hora a partir do rio Vaal e, para tanto, parte da água destinada à agricultura local e uso residencial potencialmente será desviada (IRENA, 2015); e, na Índia, uma política governamental impulsionou a expansão da irrigação na bacia ocidental do Indo-Ganges ao permitir tarifas de energia elétrica atrativas para o bombeamento de águas subterrâneas para a irrigação, deixando os lençóis em estado crítico (UNESCO, 2014).

$\mathrm{O}$ equilíbrio entre água-energia-alimentos não é só impactado pelas pressões decorrentes do crescimento populacional e econômico, mas também é influenciado pela localização geográfica (por exemplo, regiões com maior escassez de água), por eventos climáticos extremos, por variações sazonais, ondas de calor, mudanças climáticas, entre outros (IEA, 2012).

Os fatores climáticos impactam, por exemplo, a produção de grãos destinada à produção de biocombustíveis como soja, milho, cana-de-açúcar, com intensa dependência pluviométrica; aumentos de temperaturas podem reduzir a eficiência do uso da água em usinas térmicas com torres de arrefecimento (que utilizam água doce) e potencialmente reduzir a eficiência e produção energética, inviabi- lizando a planta de produção. Um caso recente da influência climática diz respeito à crise energética no sudeste brasileiro em 2014/2015, na qual a redução drástica dos índices pluviométricos acarretou a diminuição do fluxo dos rios e do nível de água dos reservatórios, reduzindo a produção de energia hidrelétrica (de grande importância na matriz energética do país) e forçando a utilização das termelétricas, com custo de produção mais elevado.

A Tabela 2 apresenta exemplos de eventos climáticos ao longo dos últimos anos que interferiram na disponibilidade hídrica e, consequentemente, na produção energética dos respectivos países.

A Tabela 3 sumariza os potenciais riscos e impactos da geração energética sobre os recursos hídricos, assim como os riscos e impactos da água na segurança energética. Os riscos associados à inter-relação água-energia apresentam impactos diretos e indiretos sobre a sociedade, a economia e as políticas governamentais (Tabela 4). Como exemplificado anteriormente, pressões energéticas excessivas sobre os recursos hídricos podem interferir na disponibilidade de água para uso doméstico e industrial, fazendo com que uma parcela da população urbana e de empresas migrem para outros locais; crises energéticas e hídricas podem causar aumento de preços de alimentos e produtos em geral; e instabilidades políticas podem surgir relacionadas à segurança energética, à redução de rendimentos agrícolas, entre outros.

Os riscos relacionados ao nexo água e energia devem ser estudados e compreendidos para que sejam reduzidos os impactos causados pela falta de sinergia. Para isso, é necessário que se observe a questão para definir os desafios a serem enfrentados e as oportunidades que podem surgir, o que será analisado na seção a seguir. 
TABELA 2 - Exemplos de impactos climáticos sobre a disponibilidade da água e produção de energia.

Localização (ano)

\section{Descrição}

\section{Geração de energia}

Uma monção atrasada aumentou a demanda de eletricidade (para o bombeamento de água subterrânea Índia (2012) para irrigação) e reduziu a geração hidrelétrica, contribuindo para apagões de até dois dias que afetaram mais de 600 milhões de pessoas.

Seca limitou a geração hidrelétrica no rio Yangtze, contribuindo para o aumento da demanda de

China (2011) carvão (e preços) e forçando algumas províncias a implementarem rigorosas medidas de eficiência energética e de racionamento de energia elétrica.

Vietnã, Filipinas O fenômeno climático El Niño provocou uma seca que durou vários meses, reduzindo a geração (2010) hidrelétrica e causando escassez de eletricidade.

Sudeste dos Estados Durante uma seca, a autoridade do Vale do Tennessee reduziu a geração hidrelétrica para armazenar Unidos (2007) água e reduziu a produção de plantas a combustíveis fósseis e nucleares.

Oeste dos Estados Uma onda de calor forçou usinas nucleares a reduzirem sua produção devido à alta temperatura da Unidos (2006) água do rio Mississipi.

França (2003) Uma onda de calor prolongada forçou a EdF a reduzir a produção de energia nuclear equivalente à perda de 4-5 reatores, com um custo estimado de $€ 300$ milhões pela importação de electricidade.

FONTE: IEA (2012).

TABELA 3 - Resumo dos riscos e impactos relacionados ao nexo água-energia.

\begin{tabular}{|c|c|c|}
\hline & Riscos & Impactos \\
\hline \multirow{2}{*}{$\begin{array}{l}\text { Riscos relacionados } \\
\text { à energia para a } \\
\text { segurança hídrica }\end{array}$} & $\begin{array}{l}\text { - Acesso limitado ou não confiável à energia } \\
\text { a preços acessíveis para extrair água. } \\
\text { - Realocação de recursos hídricos de usos } \\
\text { finais para energia. }\end{array}$ & $\begin{array}{l}\text { - Interrupção no fornecimento de água aos usuários } \\
\text { finais ou desvio de recursos de outras atividades } \\
\text { essenciais como a agricultura. } \\
\text { - Mudanças no custo de entrega de água devido aos } \\
\text { custos flutuantes de insumos energéticos. }\end{array}$ \\
\hline & $\begin{array}{l}\text { Contaminação dos recursos hídricos, } \\
\text { devido à extração de energia e processos de } \\
\text { transformação. }\end{array}$ & $\begin{array}{l}\text { Recursos hídricos tornam-se inadequados, inclusive } \\
\text { para fins de consumo, devido à contaminação, muitas } \\
\text { vezes necessitando de tratamento adicional. }\end{array}$ \\
\hline \multirow[t]{2}{*}{$\begin{array}{l}\text { Riscos relacionados } \\
\text { à água para a } \\
\text { segurança energética }\end{array}$} & $\begin{array}{l}\text { Mudanças na disponibilidade e qualidade } \\
\text { da água devido a razões naturais ou } \\
\text { causadas pelo homem (incluindo restrições } \\
\text { regulatórias sobre o uso da água para } \\
\text { produção de energia / extração de } \\
\text { combustível) }\end{array}$ & $\begin{array}{l}\text { - Redução de confiabilidade do fornecimento e } \\
\text { dependência de formas mais caras de geração. } \\
\text { • Possibilidade de fixação de preços pela água e, } \\
\text { portanto, custos mais elevados de produção de } \\
\text { energia. } \\
\text { - Redução da disponibilidade de água para as } \\
\text { fases de extração e processamento de combustível, } \\
\text { levando à redução da produção. }\end{array}$ \\
\hline & $\begin{array}{l}\text { Aumento na demanda de energia para } \\
\text { produção, tratamento e distribuição de água. }\end{array}$ & $\begin{array}{l}\text { Tensões no sistema de energia e eficiências } \\
\text { reduzidas, atendendo aos diferentes perfis de } \\
\text { demanda de água e energia. }\end{array}$ \\
\hline
\end{tabular}

FONTE: IRENA (2015). 
TABELA 4 - Alguns impactos políticos, sociais e econômicos dos riscos relacionados com o nexo água-alimentos-energia.

\begin{tabular}{|c|c|c|}
\hline Impactos & Impactos diretos & Impactos indiretos \\
\hline $\begin{array}{c}\text { Impacto sobre os } \\
\text { governos }\end{array}$ & $\begin{array}{l}\text { - Estagnação do desenvolvimento econômico } \\
\text { - Desconforto político } \\
\text { - Custo da ajuda alimentar de emergência } \\
\text { - Redução significativa dos rendimentos agrícolas } \\
\text { - Ameaças à segurança energética }\end{array}$ & $\begin{array}{l}\text { - Aumento dos custos sociais ligados ao } \\
\text { emprego e à perda de renda e perdas na } \\
\text { agricultura } \\
\text { - Riscos sobre a segurança nacional e } \\
\text { conflitos sobre recursos naturais }\end{array}$ \\
\hline
\end{tabular}

FONTE: WEF (2011b).

\section{Oportunidades e desafios do nexo água-energia}

Dada sua importância, muitos são os desafios para a incorporação do conceito do nexo água-energia no cotidiano dos governos, instituições e comunidade. Qualquer estratégia que foque em apenas uma parte do nexo água-energia-alimento sem considerar suas interconexões corre o risco de gerar graves consequências indesejadas (WEF, 2011b).

Assim, é imprescindível que a elaboração e a implantação de políticas públicas levem em conta a relação entre os setores hídrico e energético e tratem ambos conjuntamente. Da mesma forma, a organização e a comunicação entre os órgãos de governo precisam contemplar iniciativas que gerem o diálogo e a interação natural entre os dois temas, como Lindberg \& Leflaive (2015) deixam claro:
Políticas relacionadas à água, à energia e à agricultura são frequentemente elaboradas sem considerações suficientes sobre sua inter-relação ou sobre suas consequências inesperadas. O caráter setorial da abordagem de muitos governos para elaborar políticas em diferentes áreas e em diversas escalas é o fator chave para esta incoerência. Acordos institucionais precisam ser reformulados, políticas e instrumentos políticos precisam ser redesenhados para criar uma maior interação nessas áreas, em diversas escalas espaciais e temporais (Lindberg \& Leflaive, 2015).

Além disso, políticas de educação e de pesquisa e desenvolvimento tecnológico devem considerar esse nexo na definição de suas linhas de atuação. Esse é um dos pilares para o desenvolvimento e a consolidação do nexo água-energia e estas políticas devem correr no sentido de desenvolver soluções que tragam benefícios para ambas as áreas.

Nesse sentido, inovar é imprescindível, e isso envolve pensar diferentemente sobre como as 
empresas podem atender às necessidades de água e energia de seus clientes. Superar as barreiras de hoje exigirá novas ideias, abordagens e colaboração (Metzger et al., 2016).

Nesse sentido, o DOE (2014b) destaca que há oportunidades de pesquisa, desenvolvimento, demonstração e implantação tecnológica; modelagens e análise; e levantamento e organização de dados relevantes para o nexo. Além disso, cita uma série de tecnologias para sistemas energéticos mais eficientes no consumo de água e para sistemas hídricos mais eficientes em termos energéticos, e que estão em vários estágios de pesquisa, desenvolvimento, demonstração ou implantação (Figura 11 (a) e (b)).

\section{a) Tecnologias de otimização do uso da água para a produção de energia}

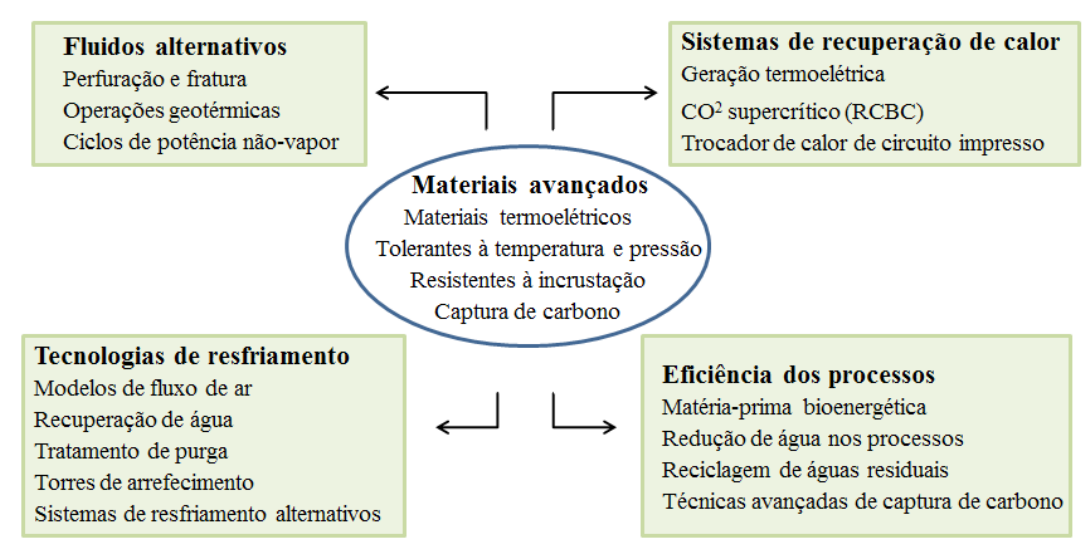

b) Desafios em energia para a água e a partir da água

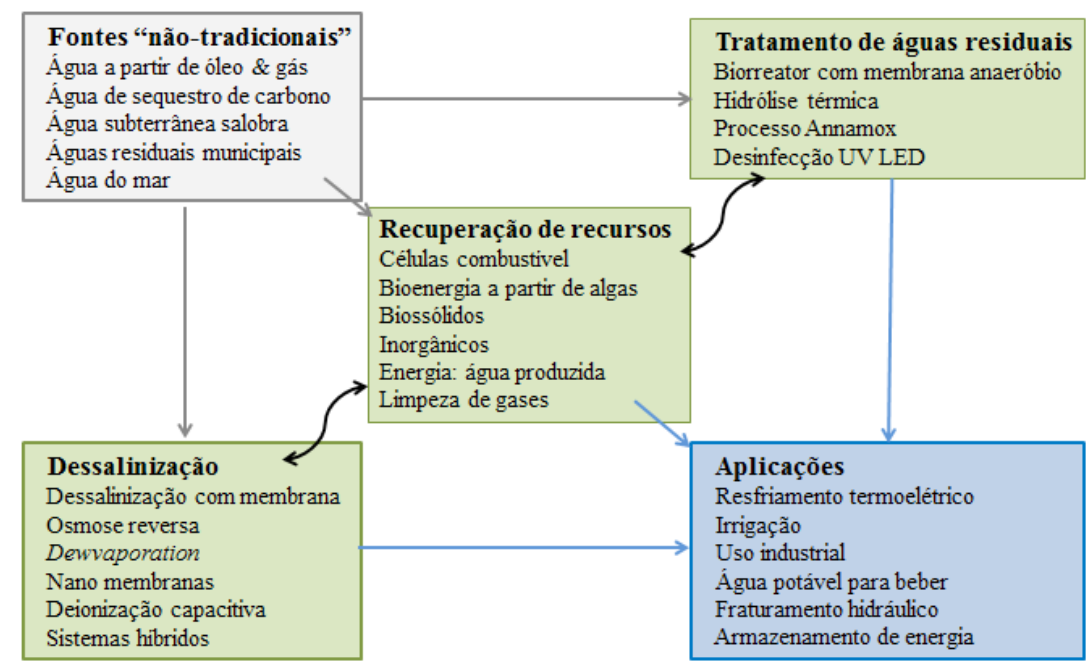

FIGURA 11 - Problemas e oportunidades tecnológicas para o nexo água-energia.

FONTE: DOE (2014a). 
Além disso, considerando que os recursos hídricos e energéticos não seguem os limites políticos de estados e países, é importante que sejam tratados e estudados em parcerias governamentais e institucionais internacionais para garantir a aplicação do nexo água-energia. O DOE (2014b) destaca que a colaboração científica internacional pode fortalecer a base intelectual em todas as áreas e ajudar a resolver problemas comuns.

Tradicionalmente, os temas água e energia são tratados separadamente pelos governos, ficando, inclusive, a cargo de setores e agências reguladoras independentes entre si. Segundo a FAO (2014), muitas vezes as decisões sobre como intervir são feitas sem coordenação intersetorial, visando resultados específicos para cada setor, e, assim, resultando em riscos e incertezas em todos os setores e escalas.

No Brasil, isso ocorre quando se analisa a existência de duas grandes agências reguladoras tratando dos temas separadamente, no caso a Agência Nacional de Energia Elétrica (ANEEL), ligada ao Ministério de Minas e Energia, e a Agência Nacional de Águas (ANA), ligada ao Ministério de Meio Ambiente. Além disso, o responsável pelo tema alimento no país é um terceiro ministério, denominado Ministério de Agricultura, Pecuária e Abastecimento.

Nesse sentido, no contexto do nexo água-energia há a necessidade de integração entre setores e de tomada de decisões em conjunto. A liderança deve ficar a cargo do poder público, mas, conforme WEF (2011b):

Especialistas argumentam que o cumprimento desses desafios é prejudicado pela existência de estruturas administrativas separadas e políticas para a agricultura, água, energia e planejamento urbano. O desenvolvimento de comissões de alto nível que reúnam departamentos governamentais, partes interessadas e representantes dos países poderia melhorar a governança do setor público, o planejamento e o fluxo de informações (WEF, 2011b).

A forma convencional de fazer política e tomar decisões em "silos" precisa dar lugar a uma abordagem que reduza os conflitos e crie sinergias entre setores, ou seja, uma abordagem do nexo (Hoff, 2011). Antecipando possíveis conflitos e sinergias, é possível projetar, avaliar e priorizar as opções de resposta que são viáveis em diferentes setores (FAO, 2014). Isso permite a redução de custos ao serem tomadas decisões mais eficazes nas soluções dos conflitos entre água e energia, o que beneficiará toda a sociedade.

Para isso, é necessário o envolvimento de várias escalas de partes interessadas, desde instituições locais até governos nacionais, comitês de bacias, bancos e agências de desenvolvimento, organizações internacionais e regionais, institutos de pesquisa e universidades, ONGs, sociedade civil e do setor privado (FAO, 2014).

Porém, uma abordagem de nexo não significa necessariamente que os temas água, energia e segurança alimentar sejam todos abordados em conjunto no âmbito de uma única intervenção; mais ênfase pode ser colocada sobre um ou outro tema, dependendo do respectivo contexto local e/ou de projeto. A perspectiva holística exige que profissionais do desenvolvimento tenham uma "visão borrada" e aceitem um certo nível de incerteza para serem capazes de explorar possíveis trade-offs entre os temas nexus (ADC, 2015).

Outro ponto importante na busca por tratar o nexo água-energia são as regulações que podem apoiar a busca pelo equilíbrio no nexo água-energia, impondo limites ou obrigando o pagamento pelo uso dos recursos hídricos ou energéticos. A IEA 
(2012) destaca como pode ocorrer essa regulamentação:

Dependendo dos direitos sobre a água ou do sistema de alocação em um determinado local, o acesso à água pode se tornar difícil, potencialmente devido à sua priorização para usos competitivos, tais como residências ou indústrias. Assim, as regulamentações ambientais podem proibir certos usos de água em circunstâncias específicas, ou impor condições à utilização mais caras, como confinamento, manipulação, tratamento, descarga, disposição, etc. (IEA, 2012).

O planejamento e a tomada de decisão, considerando os impactos de estratégias de energia nos outros setores e que de forma mais ampla apoiem uma abordagem integrada para a gestão de recursos, requerem dados qualitativos e quantitativos substanciais (IRENA, 2015). Observações de satélite, combinadas com dados in situ, fornecem informações únicas consistentes sobre o ambiente natural com o qual contamos para produzir água, energia e alimentos. Tais observações são necessárias para começar a entender os processos complexos de feedback entre o ambiente natural e as atividades humanas (FAO, 2014). Dessa forma, é imprescindível que o poder público incentive a criação e a disponibilização de bases de dados abrangentes sobre a disponibilidade e o uso dos recursos hídricos e energéticos.

Além dos dados, são necessárias ferramentas de processamento e análise desses dados que, com a definição de cenários, possam gerar informações para apoiar a tomada de decisão. Conforme a FAO (2014), os dados e as ferramentas fornecem aos gestores de recursos as informações necessárias para avaliar o estado atual do ambiente, ponderar os requisitos de diferentes usos por várias partes interessadas e gerir os recursos naturais e os ecossistemas de uma forma sustentável.
O DOE (2014a) compilou alguns dos pilares que considera importantes para aplicação atual e futura nos sistemas hídricos e energéticos em escalas local, regional, nacional e global. São eles:

- Melhorar a eficiência do uso da água doce na produção de energia, geração de eletricidade e nos sistemas de uso final de energia;

- Melhorar a eficiência energética na gestão dos recursos hídricos, no tratamento, na distribuição e nos sistemas de uso final de água;

- Melhorar a confiabilidade e a resiliência dos sistemas energéticos e hídricos;

- Aumentar o uso seguro e viável de fontes de água não tradicionais;

- Promover a operação dos sistemas energéticos zelando pela qualidade da água e pelos ecossistemas;

- Explorar as sinergias positivas entre os sistemas energéticos e hídricos.

Da mesma forma, Hoff (2011) propõe uma série de medidas que também são oportunidades para aumentar a sustentabilidade no âmbito da água, energia e segurança alimentar, como:

- Aumentar a produtividade dos recursos;

- Utilizar resíduos como um recurso em sistemas multiuso;

- Estimular o desenvolvimento por meio de incentivos econômicos;

- Coerência entre governos e políticas públicas;

- Beneficiar ecossistemas produtivos;

- Integrar redução da pobreza e crescimento verde;

- Aumentar a capacitação e a conscientização.

Os autores Lindberg \& Leflaive (2015) também sugerem maneiras viáveis de os governos 
melhorarem a coerência entre as políticas para água, energia e alimento:

- Fortalecer os mecanismos institucionais e de cooperação para reforçar a coerência;

- Promover o envolvimento e o compartilhamento de conhecimentos para conectar as esferas científica e política;

- Investir em inovação e tecnologias para conciliar objetivos políticos;

- Reconhecer diferentes contextos nacionais para estabelecer prioridades políticas;

- Promover uma abordagem de risco para a gestão da água.

Já segundo o WEF (2011b), as oportunidades e desafios para a consolidação do nexo água-energia-alimento são:

- Reconhecimento das perdas e ganhos no nexo água-alimentos-energia;

- Planejamento integrado dos recursos e envolvendo todas as partes interessadas;

- Desenvolvimento de infraestrutura focado no nível regional;

- Preços dos recursos orientados para o mercado;

- Empoderamento e implementação no nível da comunidade;

\section{Referências}

ANA - Agência Nacional de Águas. Conjuntura dos recursos hídricos no Brasil 2009. Brasília, 2009. Disponível em: $<$ http://conjuntura.ana.gov.br/>. Acesso em: jan. 2016.

ADC - Austrian Development Cooperation. Focus: Water - Energy - Food Security Nexus, 2015. Disponível em: $<$ http://www.entwicklung.at/uploads/media/Focus_Water_Energy_Food_Security_Nexus_03.pdf $>$. Acesso em: dez. 2015.
- Inovação tecnológica e financeira para a gestão do nexo.

Considerando todas essas oportunidades e alternativas sugeridas por vários autores, conclui-se que é essencial analisar as situações sempre no âmbito do nexo água-energia em todas as esferas da sociedade e incluir, conforme o caso, outros setores nesse nexo, como o de produção de alimentos.

\section{Conclusão}

Conforme apresentado nas seções anteriores, o nexo água-energia surge em um momento em que o crescimento da população mundial, as mudanças de padrão de consumo e as mudanças climáticas estão impondo condições de pressão sobre os recursos naturais. Assim, esse nexo deve ser considerado no planejamento e na execução de iniciativas e projetos públicos e privados, buscando aumentar a sinergia entre a gestão da energia e da água e reduzir os impactos causados um sobre o outro. Encontrar soluções diferentes das convencionais e sustentáveis é essencial nesse processo que demandará o envolvimento de toda a sociedade e do poder público para garantir que haja água e energia, além de alimentos, para as gerações futuras.

Bizikova, L.; Roy, D.; Swanson, D. The Water-energyfood Security Nexus: Towards a Practical Planning and Decision-support Framework for Landscape Investment and Risk Management. Winnipeg, MB, Canada: International Institute for Sustainable Development, 2013. p. 28.

DOE - U.S. Department of Energy. The Water-Energy Nexus: Challenges and Opportunities - Overview and Summary, 2014a. Disponível em: <http://energy.gov/sites/prod/ 
files/2014/07/f17/Water Energy Nexus Executive Summary July 2014.pdf>. Acesso em: dez. 2015.

DOE - U.S. Department of Energy. The Water-Energy Nexus: Challenges and Opportunities, 2014b. Disponível em: <http://energy.gov/sites/prod/files/2014/07/f17/Water Energy Nexus Full Report July 2014.pdf $>$. Acesso em: dez. 2015.

FAO - Food and Agriculture Organization of the United Nations. The Water-Energy-Food Nexus: A new approach in support of food security and sustainable agriculture. Rome: Food and Agriculture Organization of the United Nations, 2014. Disponível em: <http://www.fao.org/nr/water/docs/ FAO_nexus_concept.pdf $>$. Acesso em: dez. 2015.

Hoff, H. Understanding the Nexus. Background Paper for the Bonn 2011 Conference: The Water, Energy and Food Security Nexus. Stockholm Environment Institute, Stockholm. 2011.

ICIMOD - International Centre for Integrated Mountain Development. Contribution of Himalayan ecosystems to water, energy, and food security in South Asia: A nexus approach. Kathmandu, Nepal: International Centre for Integrated Mountain Development, 2012.

IEA- International Energy Agency. Water for Energy: Is energy becoming a thirstier resource? Excerpt from the World Energy Outlook 2012, 2012. Disponível em: $<$ http:// www.worldenergyoutlook.org/media/weowebsite/2012/ WEO_2012_Water_Excerpt.pdf>. Acesso em: dez. 2015.

IRENA - International Renewable Energy Agency. Renewable energy in the water, energy and food nexus. IRENA, 2015. p. 128.

Lindberg, C.; Leflaive, X. The water-energy-food-nexus: The imperative of policy coherence for sustainable development. Coherence for Development - Better Policies for Better Lives - Organization for Economic Co-operation and Development, n. 6, 2015. p. 12.

Metzger, E.; Reig, P.; Wen, W.H.; Young, R. S.; Owens, B. Water-energy nexus: Business risks and rewards. World Resources Institute, 2016. Disponível em: <http://www. wri.org/publication/water-energy-nexus $>$. Acesso em: dez. 2015.
OECD - Organization for Economic Co-operation and Development. Environmental Outlook to 2050. The Consequences of Inaction. Paris: OECD Publishing, 2012. Disponível em: <http://dx.doi.org/10.1787/9789264122246-en>. Acesso em: dez. 2015.

OECD/FAO. Agricultural Outlook 2013-2022, 2012. Disponível em: <www.oecd.org/site/oecd-faoagriculturaloutlook/ highlights-2013-EN.pdf>. Acesso em dez. 2015.

ONU - Organização das Nações Unidas. O futuro que queremos. Rio +20 - Conferência das Nações Unidas sobre Desenvolvimento Sustentável. ONU, 2012.

UNECE - United Nations Economic Commission for Europe. Reconciling resource uses in transboundary basins: assessment of the water-food-energy-ecosystems nexus. New York and Geneva: United Nations, 2015.

UNESCO - United Nations World Water Assessment Programme. Water for PeopleWater for Life. OECD Publishing, 2003. Disponível em: <http://www.un.org/esa/sustdev/ publications/WWDR_english_129556e.pdf $>$. Acesso em: dez. 2015.

UNESCO - United Nations World Water Assessment Programme. The United Nations World Water Development Report 2014: Water and Energy, 2014. v. 1. Paris: UNESCO, 2014. p. 230.

WEF - World Economic Forum. Water Security: The WaterFood-Energy-Climate Nexus. World Economic Forum Water, 2011a. p. 272.

WEF - World Economic Forum. Global Risks 2011. An initiative of the risk response network. World Economic Forum, 6th ed., 2011b. p. 60.

WEF - World Economic Forum. Global Risks 2015. World Economic Forum, 10th ed., 2015. p. 69.

WMO - World Meteorological Organization. High Level Segment at COP 18 Kicks off. Daily news: 4 December 2012. Disponível em: <http://www.wmo.int/pages/prog/ wcp/cop18/dailynews/20121204.php>. Acesso em: 25 de abril de 2016. 